\title{
Pronephric Duct
}

National Cancer Institute

\section{Source}

National Cancer Institute. Pronephric Duct. NCI Thesaurus. Code C34279.

An epithelial streak that arises in the cervical region of the developing embryo; is a

precursor to the Wolffian duct, which connects the pronephric kidney to the urogenital sinus. 